\title{
Approaches and Challenges of Motivating Educational Staff in Public Schools in Tanzania: Some Insights from Morogoro Municipality
}

\author{
Robert Makorere, Samuel Hudson Mrisha \\ Department of Marketing and Entrepreneurship, Mzumbe University, Morogoro, Tanzania
}

Email address:

rfmakorere@mzumbe.ac.tz(R. Makorere), samrisha@mzumbe.ac.tz (S. H. Mrisha)

\section{To cite this article:}

Robert Makorere, Samuel Hudson Mrisha. Approaches and Challenges of Motivating Educational Staff in Public Schools in Tanzania: Some Insights from Morogoro Municipality. Journal of Human Resource Management. Vol. 7, No. 4, 2019, pp. 87-92.

doi: $10.11648 /$ j.jhrm.20190704.12

Received: January 13, 2019; Accepted: October 22, 2019; Published: October 31, 2019

\begin{abstract}
The aim of this study was to highlighting the approaches and challenges of motivating educational staff in Public Schools in Tanzania: The study draws some Insights from Morogoro Municipality; six public schools were selected in Morogoro Municipality. After selecting the Municipal, 55 teachers were selected and interviewed. Data collected were analyzed descriptively. Results show that the existence of various motivation packages in the educational sector ranging from cash facilities, free housing, and health services to meals service. However, limited funds, different workers' desires, poor management, inadequate government motivation implementation strategies, limited motivation autonomy, and political intervention are found to be the challenges encountered in the course of motivating employees in the educational sector. Basing on these results, this study concluded that the process of motivating educational staff in public schools is still confronted by a number of challenges. The study therefore recommends that there is a need still to put more efforts in devising the solution to minimize the impact of such challenges. Therefore, if this recommendation is implemented, then then morally of educational staff would ultimately be realized.
\end{abstract}

Keywords: Motivation, Motivation Packages, Education Staff, Challenges, Public Schools, Teachers, Education Sector

\section{Introduction}

Motivation packages are the essential elements to hold workforce in the organizations and enable them to realize the set objectives [11]. However, the main factor which seems to pose a question on whether the motivation packages are effective or not is the occurrence of employee turnover. It is commonly agreed that high turnover rates have the negative effects to organizations and may seem to be the challenge resulting from the way organizations approach and deploy the motivation packages [18]. Employee turnover is a signal that the organization is unable to utilize the advantages found within the motivation packages [22].

The essence of deploying motivation packages is to ascertain that the working environment becomes attractive for employees to stay and continue to work towards realizing the objectives of the organizations. In this perspective, [23] argues that motivation packages influence employees' commitment as well as determine their decision to remain with the same organizations despite knowing the existence of job opportunities outside their current organizations. [21] provides that commitment and satisfaction, being the outcomes instilled by certain motivation packages, influence the extent to which employees are likely to be retained in the organizations. As far as teachers are concerned, [4] note improved working conditions as part of the motivation packages to them are looked at as the supportive factors towards their retention and continual working in the educational sector. [13], on the other hand, argues that demeaning the motivation packages at the workplace is always the factor which is likely to result into job related stress and lack of commitment on the part of employees.

Employee turnover, as the outcome of what seems to be demeaning motivation packages, has been affecting the teaching profession in the Tanzanian public service over the years. Between 2008 and 2011, about 50\% of those who joined the 
teaching profession left soon after they were employed and allocated to work in the government primary and secondary schools throughout the country (Tanzania). Within the same period, the Morogoro region suffered significantly from employee turnover due to what was reported as the newly recruited teachers not being attracted to work in certain parts of the region, especially those which were viewed as being remote with no attractive working environments [28]. Having different understanding towards the motivation driving factors between the management and workers leads to employees either to feel willing or not willing to continue working with the organizations $[5,12,15]$, further notes that, discovering what motivate employees within the motivation packages is one of the most challenging aspects confronting organizations. Every employee is motivated differently from one another in the organization [12] This is due to the fact that each employee has own wants within the motivation packages targeted by the organizations. However it is the obligation of the organizations to understand this assumption and ensure that motivation packages become the force against employee turnover [10]. Therefore, this article draws insights from the selected empirical study from the Morogoro Municipal Council for the purpose of highlighting and discussing the factors which influence employee motivation in the education sector.

\section{Related Literature}

\subsection{Concepts of Motivation and Motivation Packages}

Motivation has been defined as the psychological forces which provide behavior, purpose and direction. It refers to the predisposition to behave in a purposive manner to achieve specific unmet needs. [14] argues that when employees are not motivated, turnover is inevitable. Employee's motivation is a major factor in the success or failure for any organization. Without having the motivated workforce; productivity, morale, profits, product and service delivery are likely to suffer. Employee motivation is influenced by the employee himself or herself, the management and the environment [2].

Based on Locke and Latham's integrated model of work motivation, employees are motivated in various ways. These ways are well explained through the following theories, namely: Maslow's need hierarchy, Mc Clelland's personality-based approach, Vroom's theory, Locke and Latham's goal theory, Bandura's self-efficacy theory, Weiner's attribution theory, Herzberg's job characteristics model, the organizational commitment theory and Adam's equity theory. These theories attempt to explain employees' behavior. They provide understanding to both managers and employees on how to approach employee motivation [6]. Lindner's approach to employee motivation and Nelson's ten ways to motivate today's employees are the new approaches to employee motivation [9].

Motivation packages are viewed within the framework of work contents basing on the type of work employees do.
These include remuneration, promotion and recognition for the work done. Other things seen as motivation packages to employees include working conditions which provides the opportunities to mix with colleagues, provision of working facilities and fostering of the interpersonal relations. Likewise, motivation packages are also seen from the point of view of the benefits which are likely to be obtained by employees, these include such benefits as pension, medical schemes and leave allowance. Other motivational factors which also may be viewed as part of the motivation packages at the workplace include promotion of long-term relationship, provision of good wages, appreciation for job well done, personal loyalty to employees, opportunities for development and growth within the company, and the organizations being sympathetic to employees' personal concerns $[11,16]$.

Therefore, motivation packages are within the overall concept of compensation strategies. That means they are defined as the deliberate utilization of the pay system as the essential integrating mechanism through which the efforts of employees are directed towards the achievement of organization strategic objectives. Moreover motivation packages are the management tools which aim at influencing employees' behaviors and enable them to hopefully contribute towards achieving the organizational objectives. In this way, motivation packages are used as a business strategy for improving organizational performance. However, the failure to properly utilize the motivation packages may lead to employee turnover $[6,17]$.

\subsection{Approaching Employee Motivation}

To stay competitive organizations must invest in effective strategies to motivate staff. According to [3], employees are differently motivated; some people are motivated by money, others by professional development, flexible schedules, or sense of accomplishment. Thus, understanding the factors that motivate employees at the workplaces is the key factor to gain the human resource advantage towards realizing the objectives of the organizations [25]. However, in the course of approaching employee motivation, there are challenges which may be encountered [9]. These challenges are shown in Figure 1 below and are associated with the selection of the right motivation packages in the course of influencing employees' behavior for achieving the organizational goals.

\subsection{Influences on Employee Motivation}

The study [24] provides that motivating employees in organizations encompasses the following critical factors: employee engagement, organizational vision and values, management acknowledgement and appreciation of work well done, and overall authenticity of leadership. It is further argued that employee are expected to come to the workplace with the intrinsic motivation and desire to be successful, be value-added and contribute in achieving the vision of an organization. In turn the employers should provide resources, opportunities, recognition and proper work environment for employees to be successful [7, 14]. 
On the other hand, [1] advocate the important ways to motivate employees in the organization. These include the following: to provide employees with the information and resources they need to do a good job; to ask employees for their input by involving them in decision that affects their jobs, to find out directly from employees what motivates them; to personally congratulate employees for their excellent work, to recognize the needs of employees, to establish good channels of communication-be (physically) accessible and available; to use performance as the basis for promotion, to have promotion from within policy, to publicly recognize employees for good work (if culturally appropriate to do so publicly), to include recognition as part of morale- building activities to celebrate group success, to have clear goals; and to foster a sense of community.

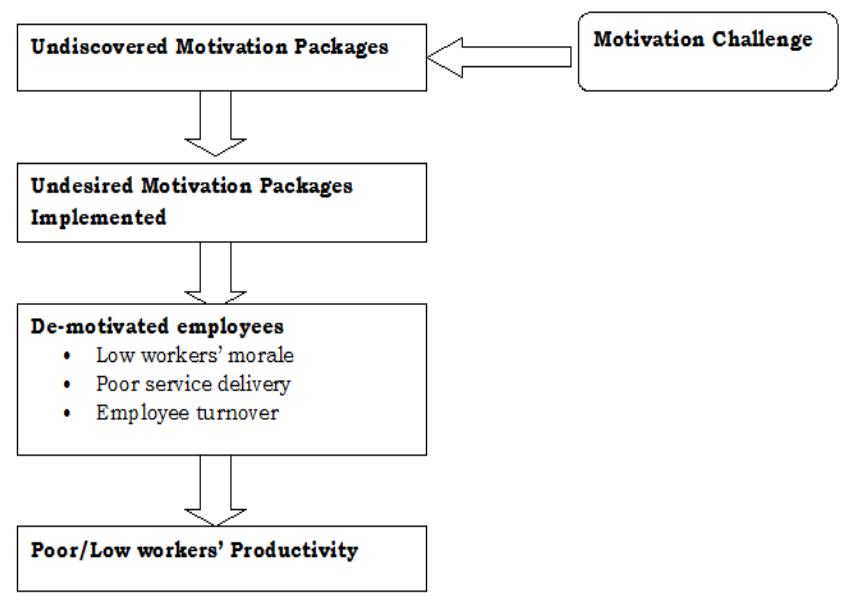

Figure 1. Problem of discovering what motivates Employees.

\subsection{Need for Motivated Employees at the Workplace}

Why do we need motivated employees? Motivated employees help organizations survive [23]. Motivated employees are needed in our rapidly changing workplaces and competitive market environments. Motivated employees and their contributions are necessary for the organization's survival and success. Motivated employees are more productive. To be effective, managers need to understand what motivates employees within the context of the roles they perform $[5,7,12,25,26]$.

\section{Materials and Methods}

\subsection{Sampling and Data Collection Method}

The selection of a sample from the population is commonly used in economics, marketing and other disciplines because of limitations of covering the whole population $[4,20]$. Sampling theory provides an opportunity to minimize cost and to achieve acceptable results $[14,16]$.

This study employed a sample size of 55 respondents. This was because of budget constraints. Moreover, a sample size of 55 was sufficient as [25] argues that a sample size of more than 30; and less than 500 is sufficient [20] On the other hand, the study employed convenience sampling technique to arrive at a sample size of 55 based on the accessibility and willingness of respondents to participate in the study.

A pilot survey to pre-test data collection instruments and to gain familiarization with the study areas was conducted in three public secondary and primary schools namely Kilakala, Kihonda, and Uluguru. Using a closed- and open-ended administered questionnaire, data was then collected on motivation packages available to public primary and secondary teachers; consequences of the approaches on educational staff motivation in Selected Wards and challenges of employee motivation process in government schools. Questionnaires were administered by two trained enumerators together with the researcher from January, 2018 to May, 2018.

\subsection{Analytical Technique}

Descriptive analysis employed in describing approaches and challenges of motivating public staff in the education sector in Tanzania. Therefore, descriptive statistic was used in analyzing of data using frequencies and percentages.

\section{Results}

\subsection{Motivation of Educational Staff: Some Insight from Morogoro Municipality}

This article, basing on the data collected from fifty five education staff drawn conveniently from the government primary and secondary schools in the six purposively selected wards (Mazimbu, Boma, Kingo, Kichangani, Kihonda and Lukobe) in Morogoro Municipality, reveals two main types of motivation packages available in the education sector. These types are direct and indirect motivation packages.

\subsection{Direct and Indirect Motivation Packages}

Direct motivation package include the material packages in the form of cash, housing, health, and meals facilities. The indirect motivation packages refer to the moral packages. Most importantly the indirect motivation packages are in the form of moral appreciation system delivered to the educational staff in the schools found in the selected six wards of the Morogoro Municipal Council as shown in Table 1.

Table 1. Motivation Packages Available for public secondary teachers $(n=55)$.

\begin{tabular}{lll}
\hline Motivation Packages & Frequency & Percent \\
\hline None & 15 & 27.3 \\
Free Housing Facilities & 7 & 12.7 \\
Free Lunch (Afternoon) & 3 & 5.5 \\
Health Facilities & 55 & 100 \\
Cash Facilities & 10 & 18.2 \\
Moral Appreciation System & 11 & 20 \\
\hline
\end{tabular}

Source: Survey Data (2018)

As indicated in Table 1 above, the findings from the 
survey conducted in the six selected wards show that fifty five education staff who responded to the questionnaires had different opinions and views regarding the motivation packages available in their respective schools as follows: The survey findings show that out of 55 respondents who responded to the questionnaires, $15(27.3 \%)$ seemed to be unaware of the motivation packages available to staff in their schools. Cash facilities as the common and quickest motivation package used in the schools were mentioned by $10(18.2 \%)$ respondents as being available. Cash was given to the teachers who meet or exceed the schools' targets. For instance, the respondents from primary and secondary education declared that for those teachers with students who have scored " $A$ " in their subjects in the national examinations are awarded a token ranging from Tshs 10,000 to 20,000 per " $A$ " scored for the job well done as the appreciation.

Moral appreciation is an indirect motivation package used in some schools [8]. This motivation package usually is given to staff orally, there is no material package issued to staff. Most of the staff who did excellent job, the manager or supervisor preferred to say "thanks you for the job well done" or "shows some kind of moral appreciation in front of the colleagues". In some cases, supervisor tended to show his/her appreciation in form of certificate of appreciation for job well done. Out of 55 respondents who responded to the questionnaires, $11(20 \%)$ indicated that moral appreciation was the kind of motivation package used in their schools. This group of the respondents pointed out that moral reward was used despite being less valued compared to material packages such as cash facility. Provision of housing facilities as something to motivate educational staff was also noted in the six selected wards of the Morogoro Municipal Council. The survey revealed that out of 55 respondents who responded to the questionnaires, 7 (12.7\%) mentioned free housing facilities as their direct motivation package. Despite being one of the motivation packages, the housing facilities were found to be inadequate as these facilities covered less that $5 \%$ of the educational staff in the six selected wards in the municipality. Hence, very few educational employees were found to be motivated by this package.

All $55(100 \%)$ respondents in the survey mentioned health facilities in the form of National Health Insurance Fund (NHIF) as one of motivation packages available at their workplaces. The respondents noted that they usually pay for this service via the deductions from their monthly salaries. However the respondents had the view that health facilities become an effective motivation package when one receives better services through their insurance without being demanded to pay in cash for the services. Out of 55 respondents in the survey, $3(5.5 \%)$ mentioned free breakfast/ tea provided to them by their supervisors or heads of schools as part of the motivation packages. Some schools in the six selected wards in the municipality offer meals as the motivation strategy to facilitate their teachers to stay longer in the school premises for teaching purposes during the working hours.

\subsection{Consequences of the Approaches on Educational Staff Motivation in Selected Wards}

The respondents in this survey fell into two categories in terms of their views regarding the way their schools approached motivation packages. Out of 55 respondents who were provided with the questionnaires, $41(74.5 \%)$ seemed to have the radical mind set and they were planning to change their current job while only $14(25.5 \%)$ of respondents were indifferent as they did not plan to leave their teaching profession as shown in Table 2 below:

Table 2. Responses on whether planning to change the job or not $(n=55)$.

\begin{tabular}{lll}
\hline Job Status & Frequency & Percent \\
\hline Planning to change the current employment & 41 & 74.5 \\
Planning to remaining in the same job & 14 & 25.5 \\
\hline
\end{tabular}

Source: Surveyed Data (2018)

The-2 (74.5\%) respondents who planned to change their current jobs had the views that such motivation packages as work incentives and working environments were not attended as per their expectations and hence had not reasons to stay any longer in the teaching profession as noted here under:

\subsubsection{Poor Working Incentives}

Out of 55 respondents participated in the survey, 27 (49.1\%) complained about incentive strategies in their schools. The respondents noted that there were no any incentive strategies in place and their recommendations were not listened to, hence their option was to leave their current employer. With that, most of respondents thought to change job.

\subsubsection{Poor Monthly Salary}

Out of 55 respondents who responded to the questionnaires, $17(30.9 \%)$ said they were planning to change their current job because of poor salaries. This seemed to be main challenge from the direct motivation packages expected by the ones who work in the teaching profession. Thus to these respondents, the failure to receive satisfactory salaries was the reason for them to leave.

\subsubsection{Poor Working Environment}

It is obviously that every employee wishes to work in excellent and attractive working environment for better output as well as staff motivation. However, out of 55 respondents who responded to the questionnaires, 7 (12.7\%) complained about working environments and noted that the working conditions were not friendly. These respondents mentioned that they encountered poor office equipment and teaching equipment. They also noted that such facilities as toilets were damaged beyond repair and situation was not hygienic at all. 


\subsection{Challenges of Employee Motivation Process in Government Schools}

Table 3 shows different factors which challenge employee motivation process in education sector:

Table 3. Challenges encountered in the Employee Motivation in the Education Sector $(n=55)$.

\begin{tabular}{lll}
\hline Motivation Packages & Frequency \\
\hline Limited Funds & 18 \\
Poor Management Skills & 8 & 32.7 \\
Different Worker Aspiration/desires & 14 \\
Political Intervention & 23.6 & 3 \\
Poor Government Motivation and Evaluation Criteria & 2 & 6 \\
No identified Criteria to Consider & 5.6 \\
Limited Motivation Authority & 5 & 3.1 \\
\hline
\end{tabular}

Source: Surveyed Data (2018)

\subsubsection{Limited Funds}

The organization can formulate good motivation strategies in a form of cash material but if funds are not available nothing can be realized. Out of 55 respondents, $18(32.7 \%)$ mentioned that fund was the limiting factor. Most of respondents specifically supervisors and head teachers/mistress failed to motivate their staff to perform well because they had limited funds. It was observed that most of the supervisor or management did not have enough budgets for staff motivation because most of motivation packages operated under the government directives and guidelines.

\subsubsection{Different Workers Needs/Desires}

Each employee had different goals, desires and aspiration during the recruitment and after the recruitment process. The study found that most of respondents interviewed had their own desire different from the employer. Some wish their employers need to improve their monthly salary and incentives, including the provision of housing and transport facilities. However such needs and desires give employers hard time in determining which one among these should be given first priority. Out of 55 respondents, 13 (23.6\%) said difference in workers desires/aspiration from their employers could be a challenging factor for motivation process.

\subsubsection{Poor Management Motivation Skills}

Poor management motivation skills regarding how to determine appropriate motivation packages were a challenge. Out of 55 respondents, 8 (14.5) noted poor that management skill was a challenging factor to the heads of schools. Most of them have failed to plan or identify the kind of motivation packages needed by the educational staff.

\subsubsection{Poor Government Motivation Implementation and Evaluation Strategies}

Poor government motivation implementation and evaluation strategies seem to be a challenge encountered in the provision of the motivation packages. On this, $6(10.9 \%)$ of respondents who responded to the questionnaires commented that motivation process becomes challenging due to poor motivation and implementation strategies from the side of the government.

\subsubsection{No Identified Criteria to Consider}

Most of head teachers who responded to the questionnaires noted that there were no identified criteria to consider in the motivation process in the schools from the six wards of the municipality. Out of 14 respondents of whom, $5(9.1 \%)$ responded that the criteria to motivate the teachers were not known to them.

\subsubsection{Limited Motivation Authority/Autonomy}

Limited motivation authority or autonomy held by managers or supervisors of government institutions, in particular primary and secondary schools was among the factors which affected the motivation process within the education sector. Out of 55 respondents, 39 (5.5\%) noted that their leaders in the schools had limited authority or autonomy to spend government budgets for motivation purposes as such budgets come with the conditions attached.

\subsubsection{Political Intervention}

Out of 55 respondents, $2(3.6 \%)$ indicated that to some extent the political intervention had the direct influence on the way motivation packages were approached. Political intervention was one of challenges limiting the effective implementation of the motivation packages in the schools located in the selected wards. Several times teachers and other government staff salary increments were delayed for no apparent reason.

\section{Conclusion}

The process of motivating individuals in the education sector is still confronted by a number of challenges. That means there is a need for those concerned to put more efforts in devising the solution to minimize the impact of such challenges. This seems to be the necessary conditions if the aim is to ensure that the education sector delivers according to the expectations. Having divergent views regarding the motivation packages found in the education sector seems to be the main challenge in the process of finding the balanced views and determine the way educational staff motivation should be approached. 


\section{References}

[1] Basha, K and Hanter, A (2017), The Effect of Relation Factors on Organizational commitment: An Investigation of High Technology Employees, South Africa.

[2] Birkin, R. (2006), Recognizing and Rewarding Employees, San Francisco. McGraw-Hill.

[3] Beardwell, J. \& Claydon, T. (2007), Human Resources Management: A contemporary Approach, Prentice Hall, London.

[4] Berry, B., Smylie, M., \& Fuller, E. (2018), Understanding Teachers working condition: A review and look to the future, Hillsborough, NC: Centre for teaching Quality.

[5] Bowen, B. \& Radhakrishna, R. (1991), Job Satisfaction of Agricultural Education Faculty: A Constant Phenomenon, Journal of Agricultural Education, 32 (2). 16-22.

[6] Drafke, M. \& Kossen, S. (2002), The Human Side of Organizations, Upper Saddle River, New Jersey, Prentice Hall.

[7] Farag, A. A. (2008), Multigenerational Nursing workforce value differences and work environment: Impacts on RNS' turnover intentions, Western Reserve University.

[8] Gubman, E (2003), The Engaging Leader: Winning with today's Free Agent Workforce, Trade Publishing, Dearbon.

[9] Gwavuya, F. (2015), Leadership Influences on Turnover Intentions of Academic Staff in Institutions in Zimbabwe. Academic Leadership Journal, (9), 1-15.

[10] James, M (2009), Management and Organization Behaviour in Africa, London.

[11] Jackson, K. (2007), Evaluating the influence of Tanzania culture on church leadership styles, Journal of Management, 2 (8), 21-30.

[12] Kovach, K. A. (1987), What Motivates Employees? Workers and supervisors give different answers, Business Horizons, 30. Pp 58-65.

[13] Korkmaz, M. (2007), The effect of leadership styles on organizational health, Educational Research Quarterly, 30 (3), $22-54$.

[14] Kreitner, R. (1995), Management Styles, Boston: Houghton Mufflin Company.

[15] Lin, P. (2017), The Correlation between Management and Employment Motivation in Sasol Polypropylene Business South Africa, Pretoria, South Africa.

[16] Lephalala, R. P. (2006). Factors influencing Nursing turnover in selected private hospitals in England. University of South Africa, South Africa.

[17] Maslow, A. (1970), Motivation and Personality, Lynne Rienner Publisher Ltd, New York.

[18] Mrayyan, M. T. (2005), Nurse Job Satisfaction and Retention: Comparing Public to Private Hospitals in Jordan, Journal of Nursing Management, 13 (1), 40-50.

[19] Morogoro Municipal Profile Report (2012), Morogoro Municipal Strategic Plan 2008/11, Morogoro, Tanzania.

[20] Musa, J., Marsland, D., \& Sager, L. (2012). The Four Drive Model of Employee Motivation: A New Model to Increase Employee Engagement, New York, Trade Publishing.

[21] Roscoes, D. K (1975), Retention of Your Best Employees, New Jersey, Prentice Hall.

[22] Robbins, S. P (2003), Organization Behaviour: Concepts, Controversies and Applications, New Jersey: Prentice Hall International.

[23] Smith, G. P. (1994), Human Resources Management and Development Handbook, New York, The Free Press.

[24] Strachota, G. R. (2005), The Process of Management, UK. Publishing House, Bareilly.

[25] Spector, L. C. (2008), Reflections on Leadership, The Robert, K Greenleaf Center for Servant Leadership, New York: John Wiley and sons, Inc.

[26] Tull, A. T. (2005), The relationship between perceived level of synergistic supervision and job satisfaction of new professionals in student affairs administration, Florida State University, Florida.

[27] United Republic of Tanzania (2009), Standing Order for Public Services, Tanzania.

[28] Morogoro Municipal Report (2015), Public Teachers Motivation Scheme, Tanzania. 